\title{
Tuning anisotropic ion transport in mesocrystalline lithium orthosilicate nanostructures with preferentially exposed facets
}

\author{
Zhengping Ding ${ }^{1}$, Datong Zhang ${ }^{1}$, Yiming Feng ${ }^{1}$, Fan Zhang ${ }^{1}$, Libao Chen ${ }^{1}$, Yong Du', Douglas G. Ivey ${ }^{2}$ and \\ Weifeng Wei (1)
}

\begin{abstract}
$\mathrm{Li}_{2} \mathrm{TMSiO}_{4}$ ( $\mathrm{TM}=\mathrm{Mn}, \mathrm{Fe}, \mathrm{Co}$, etc.) is regarded as a new class of cathode materials for next generation Li-ion batteries because of the theoretical possibility of reversible deintercalation of two Li ions from the structure (ca. $330 \mathrm{~mA} \mathrm{hg}^{-1}$ ). Nevertheless, the silicate cathode still suffers from low electronic conductivity, slow Li ion diffusion and structural instability upon deep cycling. To solve these problems, for the first time, we propose a rational design of mesocrystalline $\mathrm{Li}_{2} \mathrm{FeSiO}_{4}$ hollow discoids with an ordered single-crystal-like structure and highly exposed (001) facets. The $\mathrm{Li}_{2} \mathrm{FeSiO}_{4}$ mesocrystals display a near theoretical discharge capacity, superior rate capability and good cycling stability. The enhanced Li storage performance is ascribed to the unique structural features with a large surface area generated from the hollow mesocrystal structure and a shortened $\mathrm{Li}^{+}$diffusion path along (001) exposed facets. This new facile, elegant synthesis method that enables the manipulation of crystal growth and subsequent improvements in the electronic and ionic kinetics and structural integrity should have a positive impact on the research and development of silicate materials as promising cathodes for next generation Li-ion batteries.
\end{abstract}

\section{Introduction}

The search for new cathode materials that can boost the energy density of Li-ion batteries (LIBs) is an ongoing global challenge $\mathrm{e}^{1-3}$. In the past two decades, a variety of layered transition-metal (TM) oxides and polyanionic frameworks have been intensively pursued ${ }^{4-10}$. Among them, orthosilicates, i.e., $\mathrm{Li}_{2} \mathrm{TMSiO}_{4}(\mathrm{TM}=\mathrm{Mn}, \mathrm{Fe}, \mathrm{Co}$, etc.), have attracted considerable attention for their high theoretical capacity with insertion/extraction of two $\mathrm{Li}^{+}$ions per formula unit $\left(\sim 330 \mathrm{~mA} \mathrm{hg}^{-1}\right)^{11}$. However, orthosilicates suffer from intrinsically poor kinetics and

\footnotetext{
Correspondence: Weifeng Wei (weifengwei@csu.edu.cn)

${ }^{1}$ State Key Laboratory of Powder Metallurgy, Central South University, Changsha, Hunan 410083, People's Republic of China

'Department of Chemical and Materials Engineering, University of Alberta, Edmonton, AB, CanadaT6G $1 \mathrm{H} 9$

These authors contributed equally: Zhengping Ding, Datong Zhang
}

capacity fading related to the insertion/extraction of more than one $\mathrm{Li}^{+}$ion from the structure ${ }^{12,13}$. The sluggish kinetics is primarily attributed to poor electronic conductivity and ionic conductivity. For instance, the most studied orthosilicate material, $\mathrm{Li}_{2} \mathrm{FeSiO}_{4}$, has a poor $\mathrm{Li}$ ion diffusivity of $\sim 1 \times 10^{-14} \mathrm{~cm}^{2} \mathrm{~s}^{-1}$ and an extremely low electronic conductivity of $\sim 6 \times 10^{-14} \mathrm{~S} \mathrm{~cm}^{-1}$ at $298 \mathrm{~K}$, which are four orders of magnitude lower than the conductivity of its phosphate counterpart, $\mathrm{LiFePO}_{4}$ $\left(\sim 10^{-9} \mathrm{~S} \mathrm{~cm}^{-1}\right)^{12-14}$.

To address the kinetic issues, several efforts such as conductive coatings ${ }^{15-17}$, nanostructuring ${ }^{18-21}$, and heteroatom substitution ${ }^{22-26}$ have been pursued to obtain high performance $\mathrm{Li}_{2} \mathrm{FeSiO}_{4}$-based cathodes. Among these strategies, nanoscale materials have been extensively studied because nanostructures generally offer a shorter diffusion length and more surface area for the insertion/ 


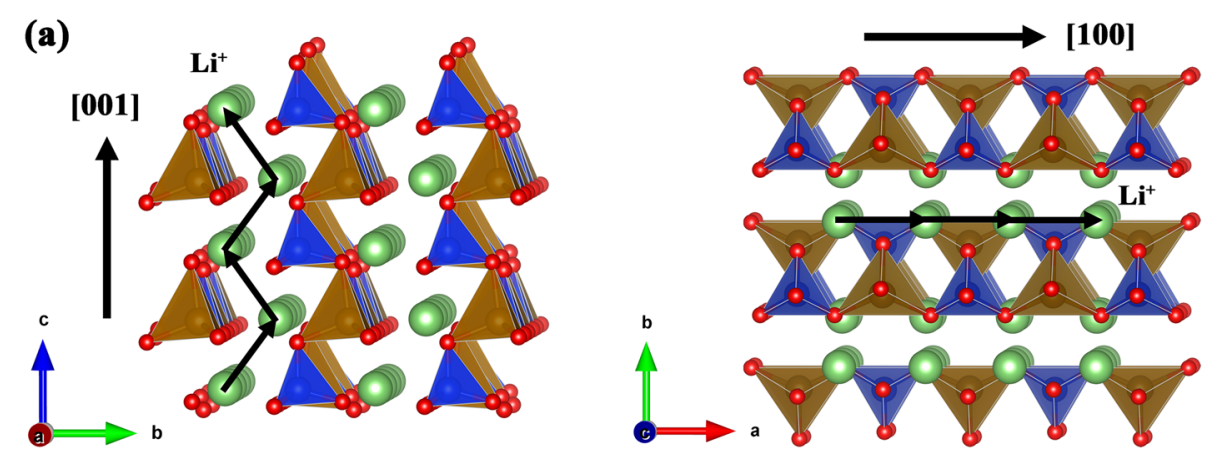

(b)

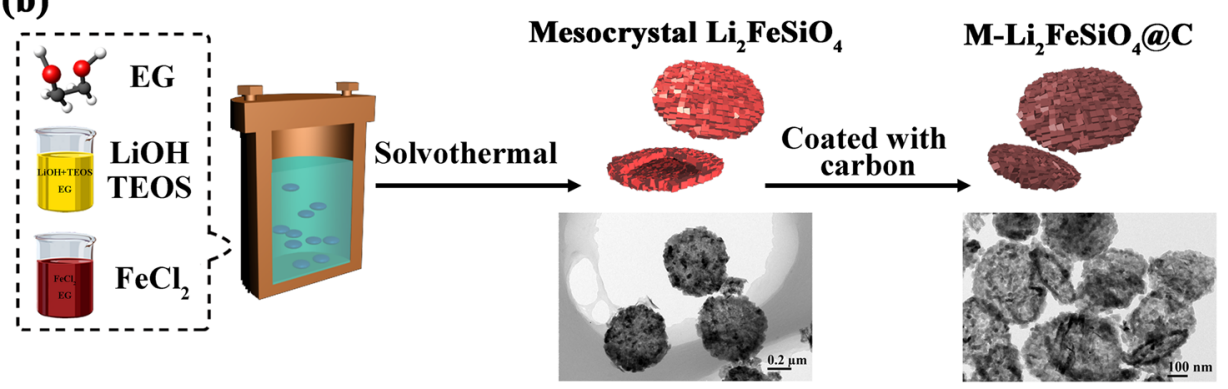

Fig. 1 Illustrations of preferred Li ion migration paths and solvothermal process for the M-LFS. a Crystal structures and diffusion pathways of $\mathrm{Li}^{+}$ions in $\mathrm{Li}_{2} \mathrm{FeSiO}_{4}$. $\mathbf{b}$ Schematic illustration of the preparation process for the mesocrystalline $\mathrm{Li}_{2} \mathrm{FeSiO}_{4}$ hollow discoids

extraction process of charge carriers. In view of the high diffusion anisotropy of $\mathrm{Li}_{2} \mathrm{FeSiO}_{4}$, tailoring the crystallographic facets and hierarchical structures of electrodes is of great importance for the electrochemical performance ${ }^{19,27}$. Theoretical calculations indicate that for $\mathrm{Li}_{2} \mathrm{FeSiO}_{4}$ with the $P m n 2_{1}$ space group, Li cations preferentially diffuse two-dimensionally along the $a / c$ plane perpendicular to the $b$-axis in the [001] and [100] directions, with Li-vacancy migration energy barriers of $0.97-1.05 \mathrm{eV}$ and $0.85-0.90 \mathrm{eV}$ in the lithiated and delithiated states, respectively ${ }^{12,28}$. Consequently, if the exposed facets of $\mathrm{Li}_{2} \mathrm{FeSiO}_{4}$ materials are parallel to the (100) and (001) planes, the kinetics of the $\mathrm{Li}$ cation insertion/extraction process would be substantially enhanced compared to randomly oriented materials, as described in Fig. 1a.

In addition to the diffusion kinetics within a primary particle, the rate performance of the electrodes depends more on the interparticle transport of $\mathrm{Li}$ cations and electrons ${ }^{29}$. Hierarchical electrode materials, assembled with oriented primary nanoparticles, have therefore been developed to obtain improved rate performance ${ }^{29-31}$. For instance, Wu's group demonstrated hierarchically structured $\mathrm{Li}_{1 \cdot 2} \mathrm{Mn}_{0 \cdot 6} \mathrm{Ni}_{0 \cdot 2} \mathrm{O}_{2}$ cathodes with a high percentage of (110) exposed planes at the surface. This hierarchical cathode material exhibited excellent rate performance due to enhanced Li diffusion kinetics ${ }^{32}$. Qi's group prepared anatase $\mathrm{TiO}_{2}$ mesocrystalline anode materials with a single crystal-like superstructure that consisted of periodic arrangements of numerous oriented $\mathrm{TiO}_{2}$ nanocrystals $^{33}$. This unique mesocrystal electrode demonstrated superior rate capability relative to a typical $\mathrm{TiO}_{2}$ nanoparticle electrode under fast charge-discharge conditions. The ordered mesocrystalline structure offers efficient interparticle electronic conduction, and the uniformly porous structure of the mesocrystals guarantees perfect contact with the electrolyte and leads to fast $\mathrm{Li}$ ion transport between the mesocrystalline electrode and the electrolyte.

Motivated by this concept, we propose a facile and versatile solvothermal strategy (Fig. 1b) to fabricate $\mathrm{Li}_{2} \mathrm{FeSiO}_{4}$ cathode materials with hollow mesocrystalline nanodiscoids as secondary particles, which are assembled by primary nanograins with enhanced growth of the electrochemically active (001) plane. A mesoscale assembly process involving the formation of metastable solid precursors to generate primary $\mathrm{Li}_{2} \mathrm{FeSiO}_{4}$ nuclei, self-assembly of $\mathrm{Li}_{2} \mathrm{FeSiO}_{4}$ nanosheets and Ostwald ripening growth is proposed for the formation of the unique, hollow discoid-like $\mathrm{Li}_{2} \mathrm{FeSiO}_{4}$ mesocrystals. Combining experiments and density functional theory (DFT) calculations, it is found that ethylene glycol (EG) molecules act as a capping agent for the manipulation of crystal growth. To ensure efficient electron conduction to the current collector, a conformal, nanoscale carbon coating was also applied to the mesocrystalline discoids. Compared to randomly oriented nanoparticles, the 
unique structure of the hollow mesocrystals enables faster $\mathrm{Li}$ ion diffusion along the (001) exposed facets and higher interparticle electronic conduction. Hence, as a cathode material for LIBs, the obtained composite possesses high reversible capacity, outstanding rate capability, and excellent cycle stability.

\section{Materials and methods \\ Materials synthesis}

Mesocrystalline $\mathrm{Li}_{2} \mathrm{FeSiO}_{4}$ hollow discoids (M-LFS) were synthesized via a solvothermal method where EG was used as the solvent, and the synthetic routes are shown in Fig. 1b. Typically, $48 \mathrm{mmol} \mathrm{LiOH} \cdot \mathrm{H}_{2} \mathrm{O}$ and 12 mmol Si(OCOCH$)_{4}$ were dissolved in $40 \mathrm{~mL} \mathrm{EG}$, while $12 \mathrm{mmol} \mathrm{FeCl}{ }_{2} \cdot \mathrm{H}_{2} \mathrm{O}$ was dissolved in $20 \mathrm{~mL}$ EG. The two solutions were then mixed and stirred for $30 \mathrm{~min}$ to form a uniform suspension solution. The precursor solution was then transported to a $100 \mathrm{~mL}$ Teflon-lined autoclave and heated to $230^{\circ} \mathrm{C}$ for $48 \mathrm{~h}$. The M-LFS products were collected, washed with deionized water and ethanol several times and then dried at $80^{\circ} \mathrm{C}$. To improve the conductivity, a nanoscale carbon coating was applied on the M-LFS by dispersing M-LFS $(0.9 \mathrm{~g})$ in a sucrose solution ( $2 \mathrm{mmol}$ sucrose in $20 \mathrm{~mL}$ distilled water) and then carbonizing it for $3 \mathrm{~h}$ at $600^{\circ} \mathrm{C}$ in an $\mathrm{Ar} / \mathrm{H}_{2}$ (95:5) atmosphere. The carbon content in M-LFS@C was approximately $12.4 \mathrm{wt} \%$ as measured by thermogravimetric analysis (TGA) (Figure S14a). For comparison, $\mathrm{Li}_{2} \mathrm{FeSiO}_{4} @ \mathrm{C}$, which is a nanocomposite with a similar grain size (Figures S15 and S16) and a similar carbon content (13.7\% carbon content, Figure S14b), was prepared via a sol-gel method using EG and citric acid as chelating agents (see the Supporting Information for details); this sample is referred to as SG-LFS@C.

\section{Characterization}

$\mathrm{X}$-ray diffraction (XRD) patterns were obtained using an $\mathrm{X}$-ray diffractometer with $\mathrm{Cu} \mathrm{Ka}$ radiation $(\lambda=1.54056$ $\AA$ ) at steps of $0.02^{\circ}$ with a counting time of $2 \mathrm{~s}$ (Bruker AXS D8 Advance, Germany). Rietveld refinement was performed using the Maud 2.33 software. Morphological and structural properties were observed using a scanning electron microscope (SEM, Nova NanoSEM 230, USA) and a transmission electron microscope (JEM-2100F, JEOL, Japan). A TEM equipped with an aberration corrector for the imaging lenses was applied to achieve high angle annular dark-field (HAADF) images and energy dispersive X-ray (EDX) mapping (FEI Titan3 G2 60-300, USA). X-ray photoelectron spectroscopy (XPS) was performed using an X-ray photoelectron spectrometer (ThermoFisher Scientific ESCALAB 250Xi, USA). XPS spectra were adjusted by the $C 1$ s peak with the binding energy (BE) of $284.6 \mathrm{eV}$. Nitrogen adsorption-desorption isotherms were measured by a Quadrasorb SI-3MP surface area and pore size analytical instrument at $77 \mathrm{~K}$. The specific surface area was calculated by the standard Brunauer-Emmett-Teller equation, and the pore size distribution was calculated on the basis of the BarretJoyner-Halenda (BJH) method ${ }^{34}$. TGA was conducted in air at a heating rate of $10^{\circ} \mathrm{C} / \mathrm{min}$ to $800^{\circ} \mathrm{C}$.

\section{Electrochemical measurements}

The electrochemical performance was tested using a coin-cell assembled in an Ar atmosphere glove box (MBRAUN LABstar, Germany). For the cathode, $80 \mathrm{wt} \%$ active materials, $10 \mathrm{wt} \%$ acetylene black and $10 \mathrm{wt} \%$ polyvinylidene fluoride were mixed in N-methyl-2pyrrolidone to form a slurry. Then, the slurry was coated onto an $\mathrm{Al}$ foil. After drying at $110^{\circ} \mathrm{C}$ in a vacuum oven, the foil was punched into plates with a diameter of $12 \mathrm{~mm}$, and the active material mass loading was $\sim 2 \mathrm{mg} \mathrm{cm}^{-2}$. Lithium metal was used as the anode, separated by a Celgard 2500 membrane and filled with 1 $\mathrm{M} \mathrm{LiPF}_{6}$ in ethylene carbonate and dimethylcarbonate $(1: 1 \mathrm{v} / \mathrm{v})$ as the electrolyte. The cells were galvanostatically charged-discharged between $1.5 \mathrm{~V}$ and $4.7 \mathrm{~V}$ vs. $\mathrm{Li}^{+} / \mathrm{Li}$ (Land CT2100A, China). Cyclic voltammetry (CV) curves and electrochemical impedance spectra (EIS) were obtained using an electrochemical workstation (PARSTAT 4000, Princeton Applied Research). The impedance spectra were recorded in the frequency range of $100 \mathrm{kHz}$ to $0.1 \mathrm{~Hz}$ with an applied alternating voltage of $5 \mathrm{mV}$.

\section{First-principles calculations}

DFT calculations were performed using the Vienna ab initio simulation package (VASP) ${ }^{35,36}$. The electron-ion interactions were described through the projector augmented wave $(\mathrm{PAW})^{37}$ method, and the exchangecorrelation functional was constructed using the generalized gradient approximation (GGA) proposed by Perdew, Burke and Ernzerhof (PBE) $)^{38}$. An energy cutoff of $400 \mathrm{eV}$ and appropriate k-point meshes were chosen to ensure that the total energies converged within $3 \mathrm{meV}$ per formula unit of $\mathrm{Li}_{2} \mathrm{FeSiO}_{4}{ }^{39-41}$. The GGA $+U$ method was applied to accurately calculate the electrochemical properties and partially correct for electron overdelocalization (and self-interaction errors) ${ }^{42}$. Within this approach, the $U$ and $J$ values were set to $5.3 \mathrm{eV}$ and $1 \mathrm{eV}$, respectively, and a ferromagnetic high-spin $\mathrm{Fe}$ state was assumed.

The cell parameters of the relaxed bulk $\mathrm{Li}_{2} \mathrm{FeSiO}_{4}$ structure are $a=6.3485 \AA, b=5.3619 \AA$ and $c=4.9720 \AA$, which are in agreement with other experimental data ${ }^{28}$. The slab technique was used to model the surfaces of $\mathrm{Li}_{2} \mathrm{FeSiO}_{4}$, in which a set of infinite layers separated by vacuum layers were repeated regularly along the surface normal. The vacuum layers were set to $10 \AA$. When 
creating a surface, the $\mathrm{SiO}_{4}$ tetrahedra were considered to be preserved due to their highly covalent $\mathrm{Si}-\mathrm{O}$ bonds. The supercell lattice parameters (including slab and vacuum) were fixed, and the inner part of the slab was frozen at the bulk positions. Only atoms near the surface were able to relax until the forces were less than $0.03 \mathrm{eV} / \AA$. Surface free energies $\left(E_{\text {surf }}\right)$ were calculated from Eq. (1):

$$
E_{\text {surf }}=\frac{E_{\text {slab }}-n E_{\text {bulk }}}{2 S}
$$

where $E_{\text {bulk }}$ is the total energy per formula unit of bulk $\mathrm{Li}_{2} \mathrm{FeSiO}_{4}$. $E_{\text {slab }}$ is the total energy of the given supercell containing $\mathrm{n}$ formula units of $\mathrm{Li}_{2} \mathrm{FeSiO}_{4} . S$ is the base area of the supercell.

EG was used as the solvent in the solvothermal conditions, and hence, the adsorption energy of the EG molecule $\left(\left(\mathrm{CH}_{2} \mathrm{OH}\right)_{2}\right)$ adsorbed on the $(1 \times 1)$ unit cell of the (001), (010), and (100) surfaces was calculated. The molecule was placed on top of the slab, and the dipole correction (VDW) was applied in the calculations. The (001), (010), and (100) surfaces had the same cutoff energy, and the corresponding $(2 \times 3 \times 1),(2 \times 1 \times 3)$ and $(1 \times 2 \times 3)$ k-point meshes were employed.The adsorption energy was calculated from Eq. (2),

$$
E_{\text {ads }}=\left(E_{\text {surf }}+E_{\text {adsorbate }}\right)-E_{\text {total }}
$$

where $E_{\text {ads }}$ is the adsorption energy, $E_{\text {surf }}$ is the total energy of the relaxed slab model, $E_{\text {adsorbate }}$ is the energy of the adsorbed molecule and $E_{\text {total }}$ is the energy of the system after adsorption of EG.

\section{Results and discussion}

\section{Structure and morphology characterization}

The powder XRD pattern for the hollow discoid-like $\mathrm{Li}_{2} \mathrm{FeSiO}_{4}$ mesocrystals (M-LFS) is shown in Fig. 2. All diffraction peaks can be indexed to the orthorhombic structure (space group $P m n 2_{1}$ ) with cell parameters $a=$ $6.2564 \AA, b=5.3408 \AA$, and $c=4.9685 \AA$ (see the Rietveld refinement results in Fig. 2a and Table S1), indicating that pure $\mathrm{Li}_{2} \mathrm{FeSiO}_{4}$ phase was synthesized by the solvothermal method $^{43,44}$. The diffraction peak broadening observed in Fig. 2a suggests that the materials are nanostructured, and the average grain size was estimated to be $\sim 19.4 \mathrm{~nm}$ on the basis of the Scherrer formula. Furthermore, it is interesting to note that, as shown in Fig. $2 b$, the peak intensities of the (210), (020), and (002) reflections deviate from those of the standard ${ }^{44}$. Generally, differences in a given peak intensity between the experimental and the reference data hint at a preferred orientation along a particular facet ${ }^{45,46}$. As shown in Fig. 2c and Table S2, the $I_{(210)} / I_{(010)}, I_{(020)} / I_{(010)}$, and $I_{(002)} / I_{(010)}$ intensity ratios for the M-LFS sample are 2.67, 1.39 and 2.02, respectively, which are much higher than the standard values of 1.083 ,
0.621 , and 1.037 for the randomly oriented standard. This is indicative of preferential growth of the (210), (020), and (002) planes in the M-LFS sample.

Representative SEM micrographs of the M-LFS material, shown in Fig. 3a, demonstrate the formation through the solvothermal process of sub-micron, discoid-shaped particles with diameters ranging from 300 to $500 \mathrm{~nm}$ and a thickness of $\sim 100 \mathrm{~nm}$. The low magnification TEM images shown in Fig. 3b, c reveal that the discoid-shaped particles consist of numerous primary particles with diameters of approximately $20-30 \mathrm{~nm}$, consistent with the abovementioned XRD analysis results. Moreover, as shown in Fig. $3 \mathrm{~b}$, the discoid-like particles possess a hollow structure, and the shell thickness coincides with the diameters of the primary particles. This unique feature indicates that the hollow discoids are assembled with a single layer of primary nanoparticles.

The corresponding nitrogen adsorption/desorption analysis results for the hollow discoids (Figure S1a) display a typical type-II isotherm with an H3-type hysteresis loop in the relative pressure $\left(P / P_{0}\right)$ range from 0.5 to 1.0. This is indicative of a porous structure and slit-shaped pores formed by nanoparticle aggregation ${ }^{34}$. The BET surface area and total pore volumes were estimated to be $65.91 \mathrm{~m}^{2} \mathrm{~g}^{-1}$ and $0.198 \mathrm{~cm}^{3} \mathrm{~g}^{-1}$, respectively (Figure S1). A pore size distribution with two peaks centered at 3-6 $\mathrm{nm}$ and $6-80 \mathrm{~nm}$ was observed, suggesting that both microand macropores are present in the M-LFS material.

The corresponding selected area electron diffraction (SAED) pattern of a single hollow discoid (Fig. 3d) shows diffraction spots with a six-fold rotational symmetry, suggesting that the hollow discoid has a "single crystallike" structure. The diffraction spots can be indexed to planes along the [001] zone axis, but the pattern is different from any simulated single crystal diffraction patterns along the [001] zone axis (Fig. 3f). As shown in a typical high resolution (HR) TEM image of the M-LFS material (Fig. 3e), many primary nanoparticles with the same [001] zone axis but different orientations exist. This was confirmed by the corresponding fast Fourier transform (FFT) patterns taken from squares A, B, and C (Fig. 3d) that are indexed as the $P m n 2_{1}$ phase along the [001] zone axis. Interestingly, if the FFT pattern of square $\mathrm{C}$ is rotated $60^{\circ}$ in a counter-clockwise direction, it will overlap with the FFT patterns of squares A and B. If the three simulated diffraction patterns from the same [001] zone axis with $\pm 60^{\circ}$ rotations are merged, one can obtain a new diffraction pattern (Fig. 3f) that is in agreement with the experimental SAED pattern (Fig. 3d). Therefore, it is reasonable to conclude that each hollow discoid is mesocrystalline in nature and is composed of nanosized grains along the [001] zone axis with a six-fold rotational symmetry. The exposed surface of the hollow discoids is thus predominantly constructed with the (001) plane 

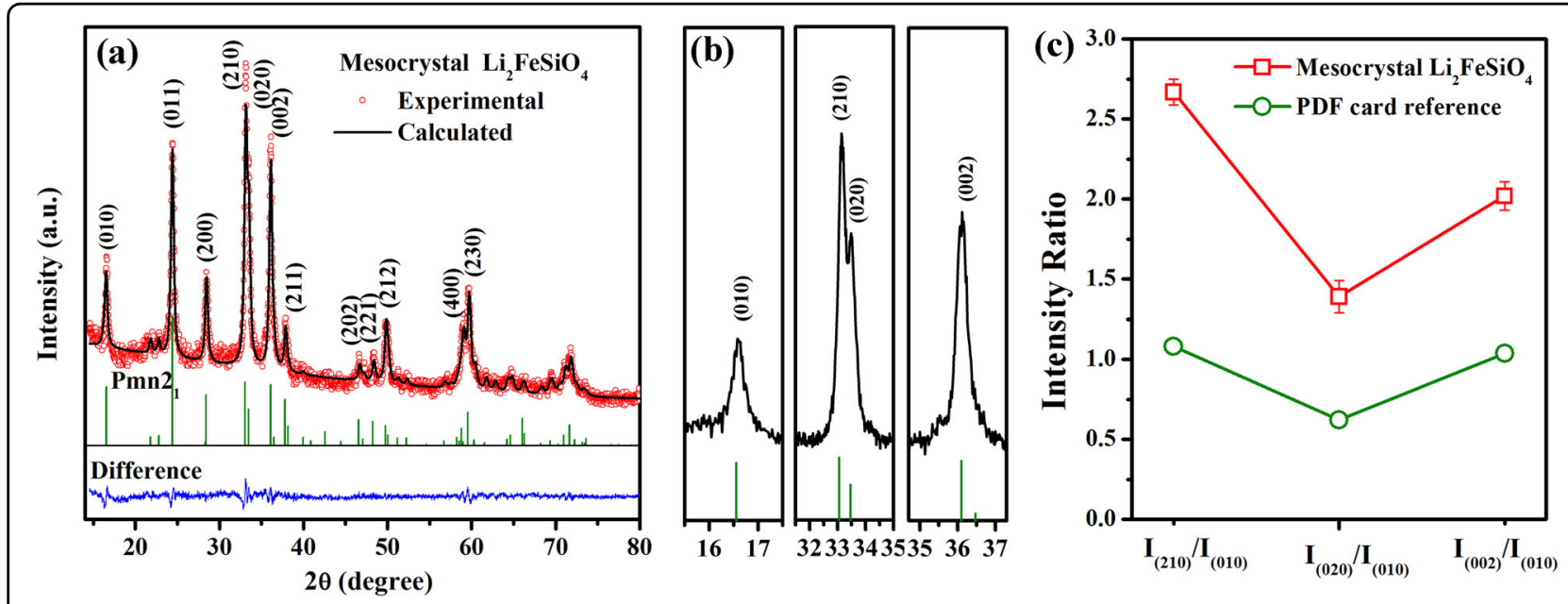

Fig. 2 Average structural characteristics of the M-LFS. a Refined powder XRD pattern of hollow discoid-like $\mathrm{Li}_{2} \mathrm{FeSiO}_{4}$ mesocrystals obtained using Maud software (Version 2.33). b Enlarged view of the diffraction pattern between $15.5^{\circ}$ and $17.5^{\circ}$ and between $31.5^{\circ}$ and $37.5^{\circ}$. c Comparison of peak intensity ratios for the experimental and reference data

perpendicular to the [001] zone axis, as shown schematically in Fig. 3f, which is consistent with the results of the XRD analysis. Note that the preferentially grown (210) and (020) planes parallel to the [001] zone axis contribute more to the grain boundaries within the hollow discoids. Therefore, due to its porous mesocrystalline features and preferentially exposed active planes at the surface, the MLFS material is expected to show superior $\mathrm{Li}^{+}$transport kinetics.

To improve the electronic conductivity, the M-LFS material was modified with a carbon coating; these materials are referred to as M-LFS@C. The XRD pattern and simulated pattern for the M-LFS@C composite are presented in Figures S2 and S3, and Rietveld refinement was carried out using the Maud software. The M-LFS@C material exhibits a mixed structure of the $P m n 2_{1}$ and $P 2_{1} / n$ phases, and the weight percentages of $P m n 2_{1}$ and $P 2_{1} / n$ were calculated as $96.35 \%$ and $3.65 \%$, respectively, as shown in Figure $\mathrm{S} 3^{43,44}$. Hence, after carbon coating, the $\mathrm{M}$ LFS@C composite still mainly exhibits an orthorhombic $P m n 2_{1}$ structure with cell parameters $a=6.2753(1) \AA$, $b=$ 5.3763(8) $\AA$ and $c=5.0201(4) \AA$, and the preferred growth of the (210), (020), and (002) planes remains intact, as shown in Figure $\mathrm{S}_{2} \mathrm{~b}^{43}$. The single crystal-like, hollow discoid-shaped morphology is also retained in the MLFS@C composite (Fig. 4a, b). Moreover, as shown in Fig. 4c, d, each nanoparticle in the mesocrystals is coated by a nanoscale carbon layer. The d-spacings of $0.267,0.536$, and $0.270 \mathrm{~nm}$ can be indexed to the (020), (010), and (210) planes along the [001] zone axis, respectively, confirming an exposed (001) plane perpendicular to the [001] axis. The HAADF-STEM image and EDX mapping of the M-LFS@C composite (Fig. 4e) confirm the homogeneous distribution of $\mathrm{C}$ along with $\mathrm{Fe}, \mathrm{Si}$, and $\mathrm{O}$, indicating that the nanoparticles are covered by a conformal carbon layer.

Two peaks at $1349 \mathrm{~cm}^{-1}$ and $1587 \mathrm{~cm}^{-1}$ are found in the Raman spectra taken from the M-LFS@C composite, corresponding to the $\mathrm{D}$ band and the $\mathrm{G}$ band, respectively (Figure S4). The intensity ratio of the $\mathrm{D}$ and $\mathrm{G}$ bands $\left(I_{\mathrm{D}} / I_{\mathrm{G}}\right)$ is 0.86 , indicating a high degree of graphitization and improved electronic conductivity. An XPS survey spectrum confirms the presence of $\mathrm{Li}, \mathrm{Fe}, \mathrm{Si}, \mathrm{O}$, and $\mathrm{C}$ in M-LFS@C (Figure S5a). As shown in Figure S5b, the deconvolution of the HR C $1 \mathrm{~s}$ spectrum displays three peaks centered at 284.8, 286.2, and $290.0 \mathrm{eV}$, corresponding to $\mathrm{sp}^{2}$-hybridized graphite-like $\mathrm{C}-\mathrm{C}$ bonding, $\mathrm{C}-\mathrm{O}$ bonding and $\mathrm{O}-\mathrm{C}=\mathrm{O}$ bonding, respectively ${ }^{4}$. The high percentage of $\mathrm{C}-\mathrm{C} \mathrm{sp}^{2}(66.1 \%)$ indicates that the carbon nanolayers are composed mostly of graphite, which is consistent with the Raman results. In addition, the Fe $2 \mathrm{p}^{3 / 2}$ peak at the BE of $711.75 \mathrm{eV}$ (Figure S5d) and the Fe 3p peak at the BE of $55.15 \mathrm{eV}$ (Figure S5c) are due primarily to $\mathrm{Fe}^{2+48}$. The $\mathrm{BE}$ difference between the main Fe $2 \mathrm{p}^{3 / 2}(711.7 \mathrm{eV})$ peak and the satellite peak $(715.5 \mathrm{eV})$ is approximately $3.8 \mathrm{eV}$. This again indicates that the majority of the Fe ions in mesocrystalline $\mathrm{Li}_{2} \mathrm{FeSiO}_{4} @ \mathrm{C}$ have a valence of $2+$, as the energy difference between the main and satellite peaks would be $\sim 8 \mathrm{eV}$ for $\mathrm{Fe}^{3+48}$. The Si $2 \mathrm{p}$ and $\mathrm{O} 1 \mathrm{~s}$ peaks centered at $103.22 \mathrm{eV}$ and $531.83 \mathrm{eV}$ (Figures S5e-S5f) can be assigned to the formation of the orthosilicate $\left[\mathrm{SiO}_{4}\right]$ structure ${ }^{49}$.

\section{Battery performance of mesocrystal $\mathrm{Li}_{2} \mathrm{FeSiO}_{4}$ hollow discoids}

M-LFS@C with (001) exposed facets, a hollow mesocrystalline structure and a conformal carbon nanocoating 

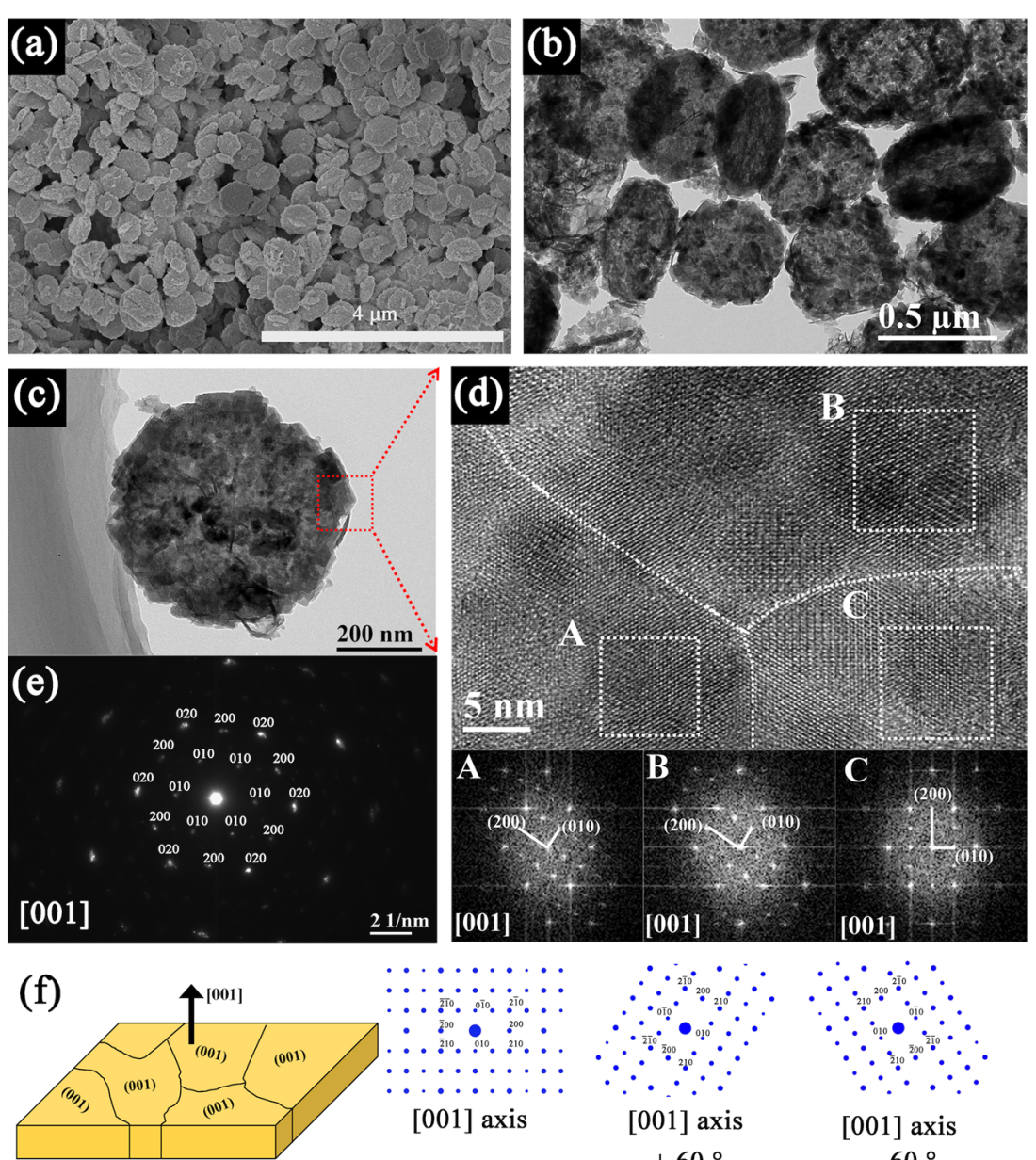

$\ldots \ldots \ldots$

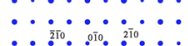

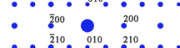

$\therefore \ldots \ldots \ldots$

[001] axis

[001] axis

$+60^{\circ}$

$\therefore \therefore$
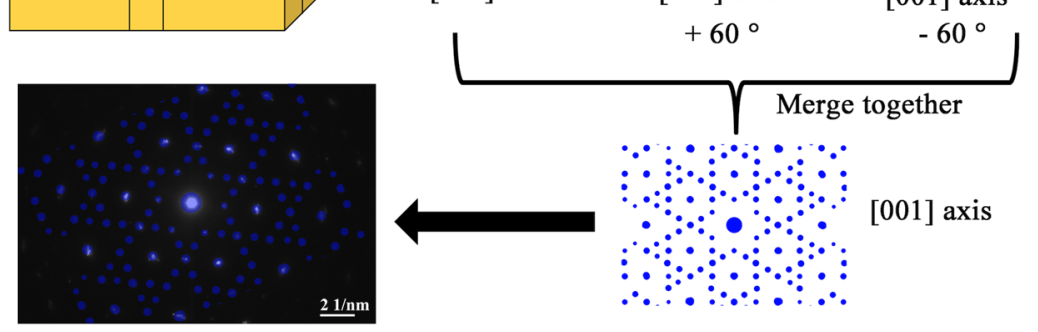

Fig. 3 Structural characterizations of the M-LFS. a Representative SEM secondary electron (SE) image, $\mathbf{b}$, c low magnification TEM bright field (BF) images and $\mathbf{d}$ SAED pattern of hollow discoid-shaped $\mathrm{Li}_{2} \mathrm{FeSiO}_{4}$ mesocrystals. e HRTEM image and FFT diffraction patterns taken from different primary nanograins in a single hollow discoid. $\mathbf{f}$ Simulated diffraction patterns of $\mathrm{Pmn}_{1} \mathrm{Li}_{2} \mathrm{FeSiO}_{4}$ along the [001] zone axis

is expected to provide excellent electrochemical performance as a LIB cathode. For comparison, the $\mathrm{Li}_{2} \mathrm{Fe}$ $\mathrm{SiO}_{4} @ \mathrm{C}$ composite with similar grain size and carbon content synthesized by sol-gel methods (SG-LFS@C) was also investigated as an LIB cathode. Figure $\mathrm{S} 6$ shows the electrochemical performance of the bare $\mathrm{Li}_{2} \mathrm{FeSiO}_{4}$ hollow discoids without the carbon coating for the first five cycles at $0.2 \mathrm{C}$. As shown in Figure S6a, the initial discharge capacity is $171 \mathrm{~mA} \mathrm{hg}^{-1}$, corresponding to $1.07 \mathrm{Li}$ ions per $\mathrm{Li}_{2} \mathrm{FeSiO}_{4}$ formula unit. In contrast, the initial discharge capacity of SG-LFS@C is $155.6 \mathrm{~mA} \mathrm{hg}^{-1}$, corresponding to $0.972 \mathrm{Li}$ ions per $\mathrm{Li}_{2} \mathrm{FeSiO}_{4}$ formula unit
(Figure S7). After carbon coating, the initial discharge capacity of M-LFS@C is further increased to 314.9 mAhg ${ }^{-1}$, with $1.97 \mathrm{Li}$ ions stored per $\mathrm{Li}_{2} \mathrm{FeSiO}_{4}$ formula unit (Fig. 5a). After 5 cycles at 0.2 C, M-LFS@C still maintains a discharge capacity of $299.2 \mathrm{mAhg}^{-1}(1.87 \mathrm{Li}$ ions), while the discharge capacity of SG-LFS@C is 143.2 $\mathrm{mAhg}^{-1}$. The midpoint voltage differences between the 5th charge and discharge cycle for SG-LFS@C, M-LFS, and M-LFS@C are 0.62, 0.53 and $0.43 \mathrm{~V}$, respectively, indicative of much less polarization and enhanced kinetics for the M-LFS@C cathode. Consequently, the hollow mesocrystalline structure with the (001) exposed facets 

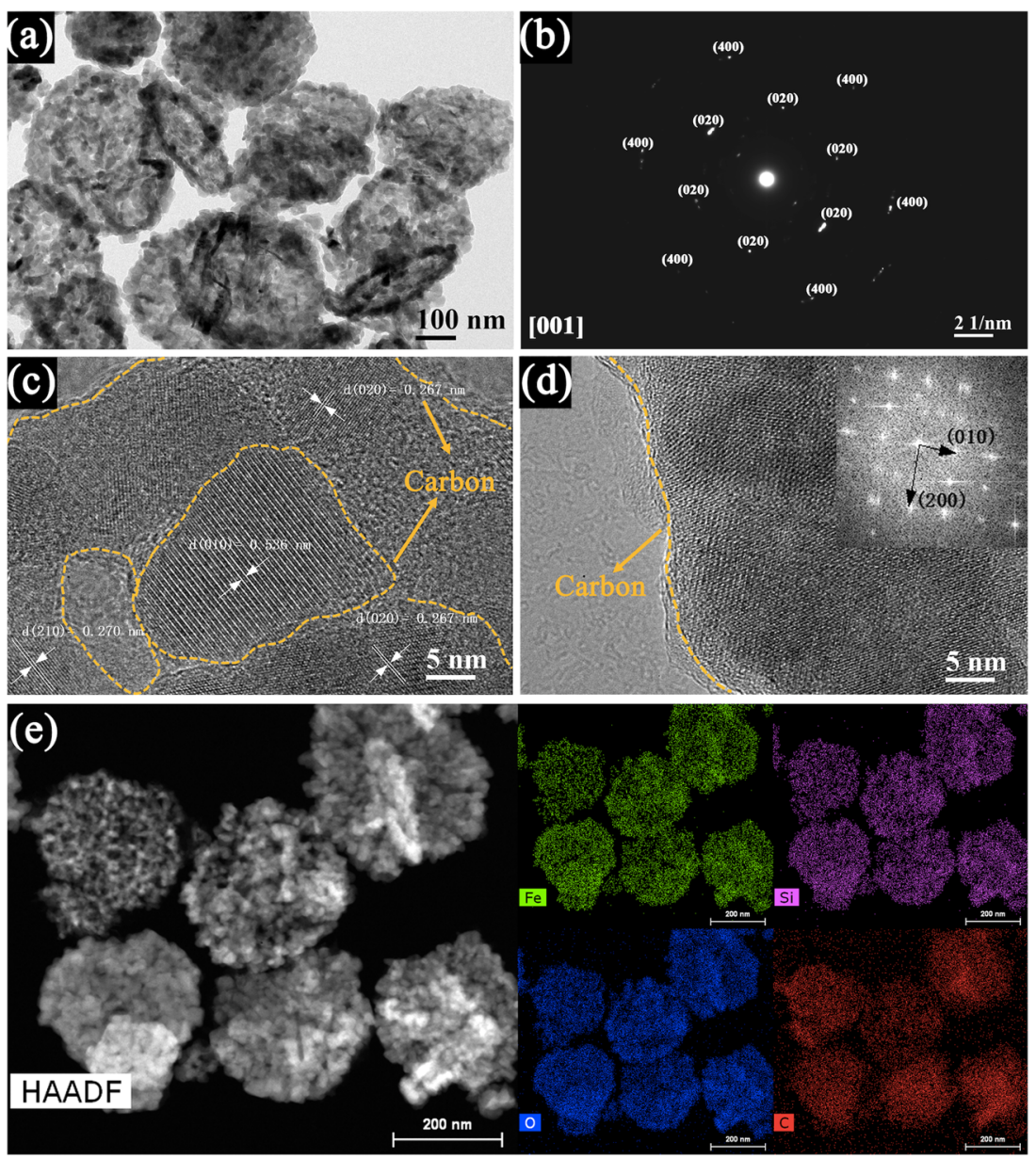

Fig. 4 Structural characterizations of the M-LFS@C. a TEM BF image, b SAED pattern and c, d HRTEM images of the M-LFS@C composite. e High angle annular dark-field (HAADF) STEM image and corresponding EDX elemental maps for the M-LFS@C composite

has a significant effect in attaining the two $\mathrm{Li}$ insertion/ extraction performance of the $\mathrm{Li}_{2} \mathrm{FeSiO}_{4}$ cathode materials.

Two voltage plateaus at $\sim 3.2$ and $4.6 \mathrm{~V}$ are observed in the initial charge curve, corresponding to the stepwise redox reactions from $\mathrm{Fe}^{2+}$ to $\mathrm{Fe}^{4+}$, which is consistent with the CV curves (Fig. 5b) ${ }^{50,51}$. Theoretically, half of the capacity $\left(\sim 165 \mathrm{mAhg}^{-1}\right)$ should be observed at the first charge plateau of $\sim 3.1 \mathrm{~V}$, corresponding to the oxidation of $\mathrm{Fe}^{2+}$ to $\mathrm{Fe}^{3+}$, and another half capacity should be observed for the second charge plateau of $\sim 4.6 \mathrm{~V}\left(\mathrm{Fe}^{3+}\right.$ to $\left.\mathrm{Fe}^{4+}\right)^{13,47,49-53}$. However, the initial charge capacity at the $3.1 \mathrm{~V}$ plateau is less than $165 \mathrm{~mA} \mathrm{hg}^{-1}\left(\sim 70 \mathrm{~mA} \mathrm{hg}^{-1}\right.$ in this work), which has also been observed in previous work $^{17,18,20,21,24,27,47,50,51,53-61}$. This commonly observed non-ideal voltage behavior has been thoroughly investigated with theoretical calculations and experimental characterization $^{13,50,52,62}$. Mustarelli et al. confirmed that voltage deviations from the ideal value are caused by the formation of undesired delithiated phases due to $\mathrm{Li}$ concentration gradients ${ }^{62}$. Moreover, Lv et al. ${ }^{51}$ employed in situ XRD/XANES analyses to understand the oxidation states of Fe during initial charging of $\mathrm{Li}_{2} \mathrm{FeSiO}_{4}$, suggesting the formation of $\mathrm{Fe}^{4+}$ for the second plateau. During the initial discharge process, a cathodic peak at $2.62 \mathrm{~V}$ and a shoulder at $2.90 \mathrm{~V}$ are observed, corresponding to the reduction of $\mathrm{Fe}^{4+}$ to $\mathrm{Fe}^{2+} 47,51$. The subsequent charge curve is fairly different from the primary charge curve (Fig. 5a), with the peak at $4.65 \mathrm{~V}$ disappearing and the peak at $3.26 \mathrm{~V}$ shifting to $3.05 \mathrm{~V}$. This phenomenon $(\sim 0.3 \mathrm{~V}$ voltage drop) is ascribed to structural rearrangements involving $\mathrm{Li}$ and $\mathrm{Fe}$ atom position exchange during the first charge ${ }^{18,44,49,63}$. After $\mathrm{Li} / \mathrm{Fe}$ cation exchange and structural rearrangement during the initial charge process, the $P m n 2_{1}$ orthorhombic structure changes to an inverse- $\beta_{\text {II }}$ orthorhombic structure as $\mathrm{Li}$ cations reinsert into the structure during the subsequent discharge process, in which Li ions diffuse mainly along the [010] and [001] directions ${ }^{47,50,51,64}$. This robust structural integrity is beneficial for maintaining $\mathrm{Li}$ 

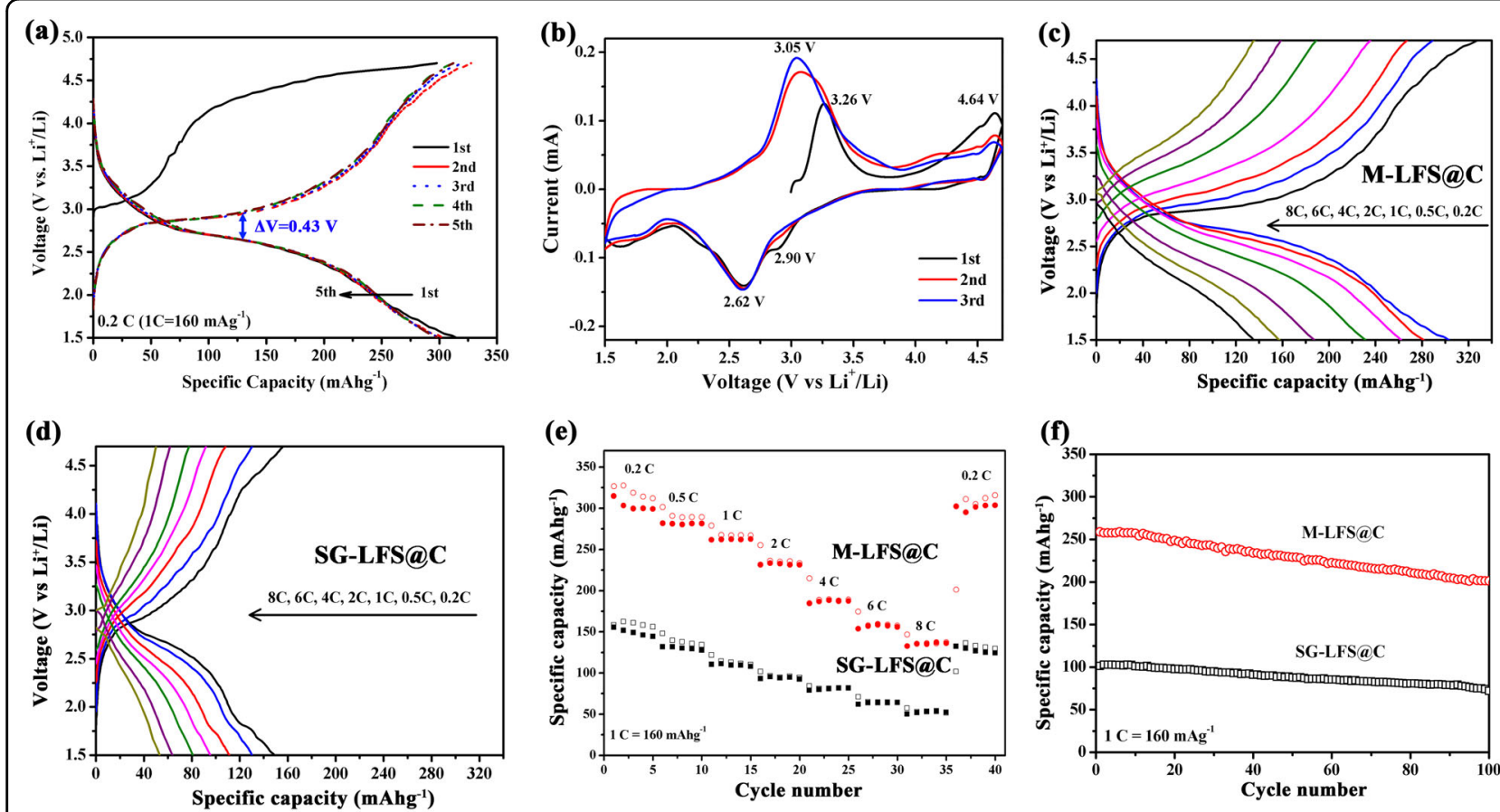

(e)

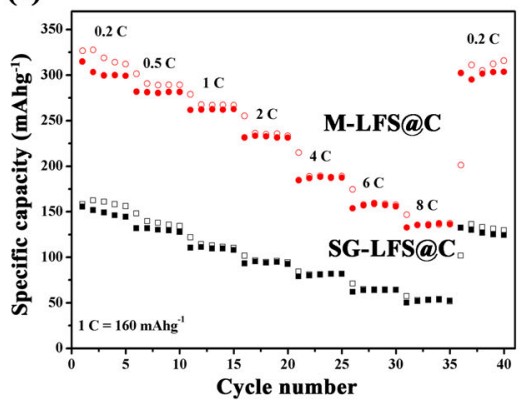

(f)

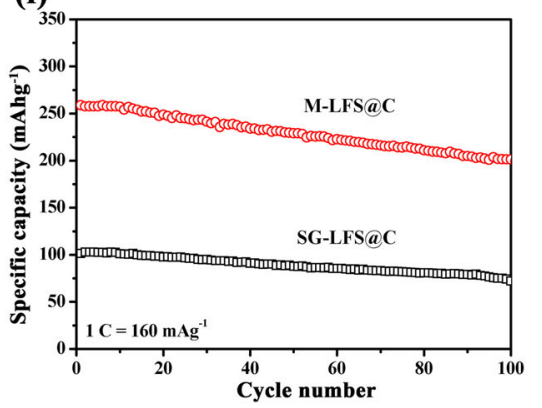

\section{(g)}

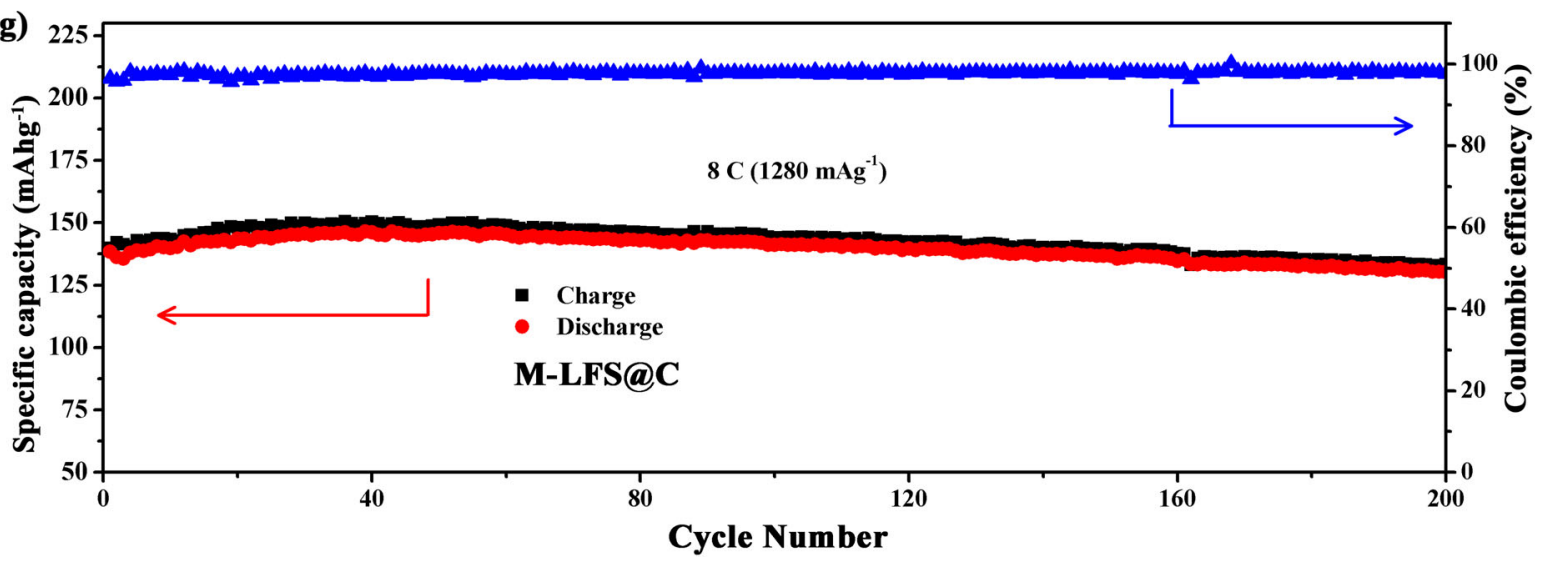

Fig. 5 Electrochemical properties of the SG-LFS@C and M-LFS@C. a Typical galvanostatic charge-discharge curves for M-LFS@C ranging from 1.5 to $4.7 \mathrm{~V}$ at $0.2 \mathrm{C}\left(1 \mathrm{C}=160 \mathrm{mAg}^{-1}\right)$. b Cyclic voltammogram curves for M-LFS@C at a scan rate of $0.1 \mathrm{mV} \mathrm{s}^{-1}$. c, d Charge-discharge profiles at different rates and e rate cycling performance for the SG-LFS@C and M-LFS@C cathodes. $\mathbf{f}$ Charge/discharge cycling performance of the SG-LFS@C and M-LFS@C cathodes at 1C. $\mathbf{g}$ Charge/discharge cycling performance of the M-LFS@C cathode at 8C

diffusion paths along the [001] direction. As shown in Fig. 5b, no deviation occurs in the anodic and cathodic peak potentials during the second and third scans, indicating that M-LFS@C exhibits excellent reversibility for $\mathrm{Li}^{+}$intercalation and deintercalation in the charge and discharge process.

To evaluate the advantages of the hollow mesocrystalline structure, the charge-discharge profiles of SG-LFS@C and M-LFS@C were collected at increasing current densities ranging from $0.2 \mathrm{C}$ to $8 \mathrm{C}$ (Fig. 5c, d). With increasing $\mathrm{C}$ rate, the charge plateau shifts to a higher voltage and the discharge plateau shifts to a lower voltage because of the polarization induced by kinetic limitations. However, it can be noted that in all situations, the discharge specific capacity of M-LFS@C is much larger than that of SG-LFS@C. For instance, the discharge capacity of M-LFS@C is 299.9, 281.6, 262.1, 231.5, 187.3, 157.5, and $135.5 \mathrm{~mA} \mathrm{hg}^{-1}$ at the rates of $0.2,0.5,1,2,4,6$, and $8 \mathrm{C}$, respectively, while that of SG-LFS@C is 155.6, 131.8, $110.5,94.8,81.7,63.8$, and $52.9 \mathrm{~mA} \mathrm{hg}^{-1}$, respectively, for the same rates. Furthermore, as shown in Figure S9, the discharge capacities for the M-LFS@C materials achieved in this work are higher than those of most other previously reported $\mathrm{Li}_{2} \mathrm{FeSiO}_{4}$ cathodes. Considering that 
both SG-LFS@C and M-LFS@C materials possess similar nanograins and carbon coatings, the significant improvement in rate capability can be attributed to the unique structure of mesocrystalline M-LFS@C, which provides short $\mathrm{Li}^{+}$ion diffusion pathways along the (001) exposed planes and a large reaction area in the hollow mesocrystal structure. Figure 5e compares the rate cycling performances of the SG-LFS@C and M-LFS@C materials. For M-LFS@C, the discharge specific capacity can recover to $303.7 \mathrm{~mA} \mathrm{hg}^{-1}$ when the rate is set back to $0.2 \mathrm{C}$ after 35 cycles, corresponding to a capacity retention of $100 \%$. In contrast, the discharge capacity of SG-LFS@C is relatively low $\left(155.6 \mathrm{~mA} \mathrm{hg}^{-1}\right.$ at $0.2 \mathrm{C}$ ), and the capacity retention is $83.6 \%$ when it is set back to $0.2 \mathrm{C}\left(130.1 \mathrm{~mA} \mathrm{hg}^{-1}\right.$ at $0.2 \mathrm{C}$ ). Figure $5 \mathrm{f}$ shows the cycling performance of SGLFS@C and M-LFS@C electrodes at 1C for 100 cycles. The initial discharge capacity of M-LFS@C is $258.8 \mathrm{~mA} \mathrm{hg}^{-1}$, and the capacity of $201.1 \mathrm{~mA} \mathrm{hg}^{-1}$ is retained after 100 cycles, giving a capacity retention of 77.7\%. For SG-LFS@C, the discharge capacity decreases from $102.9 \mathrm{~mA} \mathrm{hg}^{-1}$ to $72.1 \mathrm{~mA} \mathrm{hg}^{-1}$, corresponding to a capacity retention of $70.0 \%$. In addition, the discharge curves for the subsequent cycles (Figure S8) for MLFS@C exhibit slower potential degradation profiles at different cycles compared to SG-LFS@C. Moreover, as shown in Fig. 5g, the M-LFS@C cathode demonstrates excellent cycling stability at a high rate of $8 \mathrm{C}$. The initial discharge capacity of M-LFS@C is $138.4 \mathrm{~mA} \mathrm{hg}^{-1}$, and the capacity then gradually increases to $146.2 \mathrm{~mA} \mathrm{hg}^{-1}$ at the 40th cycle. M-LFS@C retains a discharge capacity of $130.3 \mathrm{~mA} \mathrm{hg}^{-1}$ after 200 cycles, with a capacity retention of $94.1 \%$. Additionally, the hollow mesocrystal morphology is well preserved after 200 cycles, as shown in Figure S10, suggesting robust structural stability. As discussed previously, $\mathrm{Li}_{2} \mathrm{FeSiO}_{4}$ may be attacked by $\mathrm{HF}$ generated from the $\mathrm{LiPF}_{6}$-based electrolyte by the hydrolysis of $\operatorname{LiPF}_{6}{ }^{43,65}$. When the lithium bis(trifluoromethylsulfonyl)imide (LiTFSI) system is used as the electrolyte, the cycle stability may be improved ${ }^{65}$. Further studies on the effects of different electrolytes, such as LiTFSI-based and LiDFOB-based systems, on the longterm cyclability of silicate cathodes are essential for the advancement of silicate chemistry for Li-ion cathodes.

To understand the excellent rate capability and cycling stability, the $\mathrm{Li}$ ion diffusion coefficient $\left(\mathrm{D}_{\mathrm{Li}+}\right)$ for SGLFS@C and M-LFS@C was determined using CV data collected at different scan rates (Figure S11) and was calculated on the basis of Eqs. (1) and (2) given in the Supporting Information. As shown in Table S3, the Li ion diffusion coefficient $\left(\mathrm{D}_{\mathrm{Li}+}\right)$ of M-LFS@C is higher than that of SG-LFS@C, suggesting that $\mathrm{Li}^{+}$diffusion is facilitated by the hollow mesocrystals with the (001) exposed planes. Electrochemical impedance spectroscopy (EIS) was also performed for the SG-LFS@C, M-LFS, and
M-LFS@C cathodes to evaluate their charge transfer resistance (Figure S12 and Table S4). The charge transfer resistance values for the SG-LFS@C, M-LFS, and MLFS@C cathodes are 505.7, 341.4 and 73.24 $\Omega$, respectively (Table S4). The much lower charge transfer resistance suggests a more favorable charge transfer process in the M-LFS@C cathode, in accordance with the superior rate performance of the M-LFS@C (Fig. 5e). It has been established that the reversible volumetric changes for the extraction of the first $\mathrm{Li}$ ion and the second $\mathrm{Li}$ ion are $1.57 \%$ and $6.03 \%$, respectively ${ }^{13}$. The unique hollow and mesocrystal structure could accommodate the large volume changes during the $\mathrm{Li}^{+}$intercalation and deintercalation processes, resulting in the improved cyclability observed in the M-LFS@C cathode with a long cycling life. This is also confirmed by the intact hollow mesocrystal structure after 200 cycles at the high rate of $8 \mathrm{C}$ (Figure S10).

\section{Formation mechanism of mesocrystalline $\mathrm{Li}_{2} \mathrm{FeSiO}_{4}$ hollow discoids}

The excellent electrochemical performance of $\mathrm{M}$ LFS@C is closely related to the hollow mesocrystalline structure with exposed (001) planes, so it is crucial to determine the formation mechanism of this unique structure. Precipitates collected at different reaction times without calcination were characterized using SEM, TEM, and XRD, as shown in Fig. 6a-g and S13. During the initial stage $(1 \mathrm{~h})$, the products are large irregular-shaped sediments and are composed of $\mathrm{Li}_{2} \mathrm{Si}_{2} \mathrm{O}_{5}$ and $\mathrm{Fe}_{3} \mathrm{O}_{4}$ phases, as confirmed by XRD analysis (Fig. 6g). When the reaction time was extended to $6 \mathrm{~h}$, the large sediments gradually decomposed into sub-micron discoids, which are composed of nanosheets (Fig. 6a, b and S13). Moreover, a diffraction peak corresponding to the (210) plane of $\mathrm{Li}_{2} \mathrm{FeSiO}_{4}$ appeared in the XRD pattern (Fig. $6 \mathrm{~g}$ ). As the reaction time was continually increased to $12 \mathrm{~h}$, the nanosheets self-assembled into hollow discoids (Fig. 6c, d and S13). After aging for $24 \mathrm{~h}$ or longer, most of the nanosheets were converted into equiaxed nanograins and formed hollow discoid-like $\mathrm{Li}_{2} \mathrm{FeSiO}_{4}$ mesocrystals by self-assembly (Fig. 6e, f). The diffraction peaks corresponding to the orthorhombic Pmn2 $2_{1}$ structure became stronger and sharper with increasing reaction time (Fig. 6g). Taking all the structural and morphological characterization results into account, a possible formation mechanism of the mesocrystalline $\mathrm{Li}_{2} \mathrm{FeSiO}_{4}$ hollow discoids is proposed and illustrated in Fig. 6h. Initially, large sediments composed of amorphous precursors are formed based on Reaction (1).

$$
\begin{array}{r}
4 \mathrm{LiOH}+\mathrm{FeCl}_{2}+\mathrm{Si}\left(\mathrm{OC}_{2} \mathrm{H}_{5}\right)_{4}=\mathrm{Li}_{2} \mathrm{FeSiO}_{4} \\
+4 \mathrm{C}_{2} \mathrm{H}_{5} \mathrm{OH}+2 \mathrm{LiCl}
\end{array}
$$




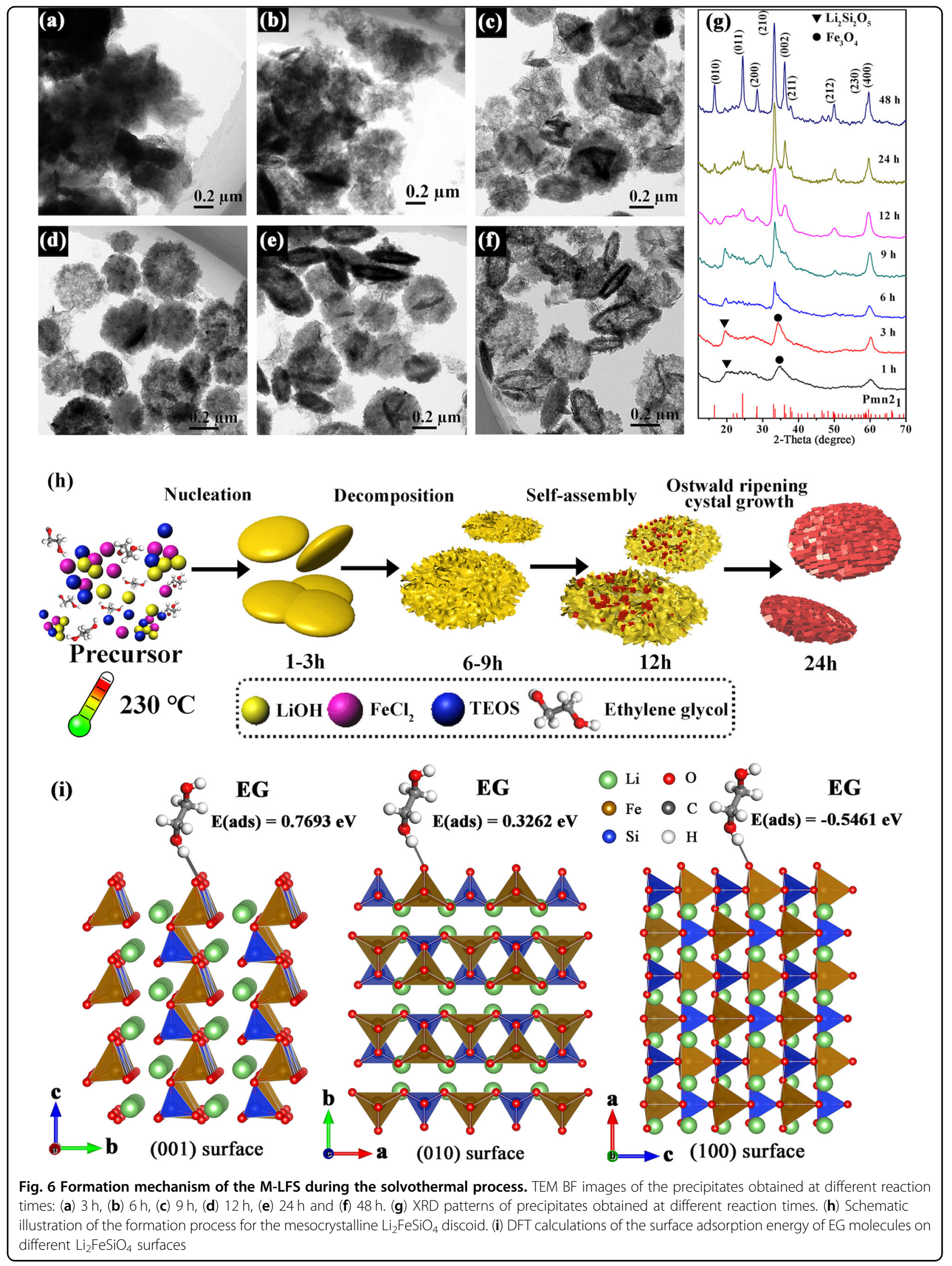


With increasing reaction time, the precursors decompose into nanosheets under solvothermal conditions. EG, used as the solvent in the experiment, can easily adsorb to the surface of the $\mathrm{Li}_{2} \mathrm{FeSiO}_{4}$ nanosheets, leading to selfassembly of the nanosheets into a discoid-like structure. Meanwhile, the metastable nanosheets tend to dissolve and recrystallize into nanoparticles via an Ostwald ripening process. Moreover, under the influence of EG, the recrystallized nanoparticles primarily grow along the same direction, resulting in mesocrystalline discoids. In addition, the inner nanosheets in the discoids are dissolved and redeposit on the shell, leading to a hollow discoid-like structure.

The formation mechanism of the preferentially exposed (001) facets in hollow discoid-like $\mathrm{Li}_{2} \mathrm{FeSiO}_{4}$ mesocrystals was further investigated by first-principles theoretical calculations. From a thermodynamic perspective, it is well-known that the growth of a certain crystallographic plane depends on its surface energy ${ }^{65,66}$. Previous studies have shown that solvents with hydroxyl groups can easily adsorb on a certain crystallographic plane, alter its surface free energy and, in turn, influence the crystal growth process ${ }^{65}$. In this work, EG with two hydroxyl groups in each molecule was used as the solvent in the solvothermal process. The EG molecules tend to absorb on the $\mathrm{Li}_{2} \mathrm{Fe}$ $\mathrm{SiO}_{4}$ surfaces via hydrogen bonds between the hydroxyl groups and the oxygen atoms in different crystal facets. As shown in Fig. 6i and Table S5, the (001) facet of orthorhombic $\mathrm{Li}_{2} \mathrm{FeSiO}_{4}$ possesses four oxygen atoms, twice the number for the (001) and (010) facets. Therefore, EG molecules show a stronger tendency to be adsorbed on the (001) surface of orthorhombic $\mathrm{Li}_{2} \mathrm{FeSiO}_{4}$. The adsorbed EG molecules will block the formation of new nuclei on the (001) surface and act as a capping agent to promote the preferential growth of the (001) facets, favoring the formation of the ordered mesocrystalline structure.

\section{Conclusions}

In summary, hollow discoid-like $\mathrm{Li}_{2} \mathrm{FeSiO}_{4}$ mesocrystals with a single crystal-like structure and highly exposed (001) facets have been successfully prepared via a solvothermal method. A mesoscale decomposition/selfassembly process, involving the decomposition of solid precursors to nanosheets, self-assembly into discoid-like products from the nanosheets and Ostwald ripening crystal growth, is proposed for the formation of the hollow discoid-like $\mathrm{Li}_{2} \mathrm{FeSiO}_{4}$ mesocrystals. Combining experimental data and DFT calculations, the EG solvent is shown to play an important role as a shape-directing agent for the manipulation of crystal growth. The mesocrystal $\mathrm{Li}_{2} \mathrm{Fe}-$ $\mathrm{SiO}_{4} @ \mathrm{C}$ (M-LFS@C) realizes near theoretical reversible capacity, superior rate capability, and improved cycling stability. The enhanced electrochemical properties can be ascribed to the unique structural features with a uniform carbon coating, a large surface area generated from the hollow mesocrystal structure and a shorter path for fast $\mathrm{Li}^{+}$diffusion along the (001) exposed facets. These results should shed light on the research and development of silicates as promising cathode materials for next generation LIBs that require higher energy and power densities.

\begin{abstract}
Acknowledgements
The authors would like to acknowledge financial support from the Recruitment Program of Global Youth Experts, the National Natural Science Foundation of China (51304248), the Innovation Program of Central South University

(2016CXS003), the State Key Laboratory of Powder Metallurgy at Central South

University and the Hunan Shenghua Technology Co., Ltd.
\end{abstract}

Conflict of interest

The authors declare that they have no conflict of interest.

\section{Publisher's note}

Springer Nature remains neutral with regard to jurisdictional claims in published maps and institutional affiliations.

Supplementary information is available for this paper at https://doi.org/ 10.1038/s41427-018-0059-9.

Received: 18 November 2017 Revised: 25 May 2018 Accepted: 27 May 2018.

Published online: 9 July 2018

References

1. Armand, M. \& Tarascon, J. M. Building better batteries. Nature 451, 652-657 (2008).

2. Islam, M. S. \& Fisher, C. A. Lithium and sodium battery cathode materials: computational insights into voltage, diffusion and nanostructural properties. Chem. Soc. Rev. 43, 185-204 (2014).

3. Bhatt, M. D. \& O'Dwyer, C. Recent progress in theoretical and computational investigations of Li-ion battery materials and electrolytes. Phys. Chem. Chem. Phys. 17, 4799-4844 (2015).

4. Masquelier, C. \& Croguennec, L. Polyanionic (phosphates, silicates, sulfates) frameworks as electrode materials for rechargeable Li (or Na) batteries. Chem. Rev. 113, 6552-6591 (2013).

5. Islam, M. S. et al. Silicate cathodes for lithium batteries: alternatives to phosphates? J. Mater. Chem. 21, 9811 (2011).

6. Arroyo-de Dompablo, M. E., Armand, M., Tarascon, J. M. \& Amador, U. Ondemand design of polyoxianionic cathode materials based on electronegativity correlations: an exploration of the $\mathrm{Li}_{2} \mathrm{MSiO}_{4}$ system $(\mathrm{M}=\mathrm{Fe}, \mathrm{Mn}, \mathrm{Co}$, Ni). Electrochem. Commun. 8, 1292-1298 (2006).

7. He, P., Yu, H., Li, D. \& Zhou, H. Layered lithium transition metal oxide cathodes towards high energy lithium-ion batteries. J. Mater. Chem. 22, 3680-3695 (2012).

8. Recham, N. et al. A $3.6 \mathrm{~V}$ lithium-based fluorosulphate insertion positive electrode for lithium-ion batteries. Nat. Mater. 9, 68-74 (2010).

9. Zhang, W.J. Structure and performance of $\mathrm{LiFePO}_{4}$ cathode materials: a review. J. Power Sources 196, 2962-2970 (2011).

10. Oh, S.M. et al. High-performance carbon-LiMnPO 4 nanocomposite cathode for lithium batteries. Adv. Funct. Mater. 20, 3260-3265 (2010).

11. Girish, H. N. \& Shao, G. Q. Advances in high-capacity $\mathrm{Li}_{2} \mathrm{MSiO}_{4}(\mathrm{M}=\mathrm{Mn}, \mathrm{Fe}, \mathrm{Co}$ $\mathrm{Ni}$, ...) cathode materials for lithium-ion batteries. RSC Adv. 5, 98666-98686 (2015).

12. Araujo, R. B., Scheicher, R. H., de Almeida, J. S., Ferreira da Silva, A. \& Ahuja, R. Lithium transport investigation in $\mathrm{Li}_{x} \mathrm{FeSiO}_{4}$ : a promising cathode material. Solid State Commun. 173, 9-13 (2013).

13. Saracibar, A., Van der Ven, A. \& Arroyo-de Dompablo, M. E. Crystal structure, energetics, and electrochemistry of $\mathrm{Li}_{2} \mathrm{FeSiO}_{4}$ polymorphs from first principles calculations. Chem. Mater. 24, 495-503 (2012).

14. Nishimura, S. et al. Experimental visualization of lithium diffusion in $\mathrm{Li}_{x} \mathrm{FePO}_{4}$. Nat. Mater. 7, 707-711 (2008). 
15. Zhang, Z. et al. Synthesis of $\mathrm{Li}_{2} \mathrm{FeSiO}_{4} / \mathrm{C}$ nanocomposite via a hydrothermalassisted sol-gel process. Solid State Ion. 276, 33-39 (2015).

16. Zhang, L., Ni, J. F., Wang, W. C., Guo, J. \& Li, L. 3D porous hierarchical Li $\mathrm{LFeSiO}_{4}$ C for rechargeable lithium batteries. J. Mater. Chem. A 3, 11782-11786 (2015)

17. Sun, $\mathrm{S}$. et al. Synthesis of $\mathrm{Li}_{2} \mathrm{FeSiO}_{4} /$ carbon nano-composites by impregnation method. J. Power Sources 284, 574-581 (2015)

18. Ding, Z. et al. Three-dimensionally ordered macroporous $\mathrm{Li}_{2} \mathrm{FeSiO}_{4} / \mathrm{C}$ composite as a high performance cathode for advanced lithium ion batteries. J. Power Sources 329, 297-304 (2016).

19. Li, D. et al. Soft-template construction of three-dimensionally ordered inverse opal structure from $\mathrm{Li}_{2} \mathrm{FeSiO}_{4} / \mathrm{C}$ composite nanofibers for high-rate lithium-ion batteries. Nanoscale 8, 12202-12214 (2016).

20. Yang, J. L. et al. $\mathrm{Li}_{2} \mathrm{FeSiO}_{4}$ nanorods bonded with graphene for high performance batteries. J. Mater. Chem. A 3, 9601-9608 (2015).

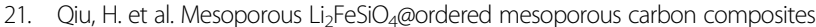
cathode material for lithium-ion batteries. Carbon 87, 365-373 (2015).

22. Zhang, Z. et al. Synthesis and characterization of spherical $\mathrm{Li}_{2} \mathrm{Fe}_{0.5} \mathrm{~V}_{0.5} \mathrm{SiO}_{4} / \mathrm{C}$ composite for high-performance cathode material of lithium-ion secondary batteries. J. Electrochem. Soc. 162, A737-A742 (2015).

23. Zhang, L.-L. et al. Study on electrochemical performance and mechanism of $\mathrm{V}$ doped $\mathrm{Li}_{2} \mathrm{FeSiO}_{4}$ cathode material for Li-ion batteries. Electrochim. Acta 152 496-504 (2015).

24. Wang, K. et al. Sn(II, IV) steric and electronic structure effects enable selfselective doping on Fe/Si-sites of $\mathrm{Li}_{2} \mathrm{FeSiO}_{4}$ nanocrystals for high performance lithium ion batteries. J. Mater. Chem. A 3, 24437-24445 (2015).

25. Yang, J. et al. Tuning structural stability and lithium-storage properties by $\mathrm{d}$ orbital hybridization substitution in full tetrahedron $\mathrm{Li}_{2} \mathrm{FeSiO}_{4}$ nanocrystal. Nano Energy 20, 117-125 (2016).

26. Toyama, T. \& Takahashi, S. Electrochemical properties of vanadium-substituted lithium silicate materials $\mathrm{Li}_{2+x} \mathrm{Fe}_{0.5-x / 2} \mathrm{Mn}_{0.5-x / 2} \mathrm{Si}_{1-x} \mathrm{~V}_{x} \mathrm{O}_{4}(\mathrm{x}=0,0.1,0.2,0.3$ and 0.4) for lithium-ion battery cathodes. J. Power Sources 294, 312-316 (2015).

27. Kageyama, H., Hashimoto, Y., Oaki, Y. \& Imai, H. Six-armed twin crystals composed of lithium iron silicate nanoplates and their electrochemical properties. CrystEngComm 17, 8486-8491 (2015).

28. Armstrong, A. R., Kuganathan, N., Islam, M. S. \& Bruce, P. G. Structure and lithium transport pathways in $\mathrm{Li}_{2} \mathrm{FeSiO}_{4}$ cathodes for lithium batteries. J. Am. Chem. Soc. 133, 13031-13035 (2011).

29. Uchaker, E. \& Cao, G. Mesocrystals as electrode materials for lithium-ion batteries. Nano Today 9, 499-524 (2014).

30. Zhou, L. \& O'Brien, P. Mesocrystals - Properties and Applications. J. Phys. Chem. Lett. 3, 620-628 (2012).

31. Wang, F. et al. Electrode materials with tailored facets for electrochemical energy storage. Nanoscale Horiz. 1, 272-289 (2016).

32. Li, $Y$. et al. Three-dimensional fusiform hierarchical micro/nano $\mathrm{Li}_{1.2} \mathrm{Ni}_{0.2} \mathrm{Mn}_{0.6} \mathrm{O}_{2}$ with a preferred orientation (110) plane as a high energy cathode material for lithium-ion batteries. J. Mater. Chem. A 4, 5942-5951 (2016).

33. Ye, J. et al. Nanoporous anatase $\mathrm{TiO}_{2}$ mesocrystals: additive-free synthesis, remarkable crystalline-phase stability, and improved lithium insertion behavior. J. Am. Chem. Soc. 133, 933-940 (2011).

34. Lowell S., Shields J. E., Thomas M. A. \& Thommes M. Characterization of Porous Solids and Powders: Surface Area, Pore Size and Density. Springer Netherlands (2004).

35. Kresse, G. \& Furthmüller, J. Efficient iterative schemes for $a b$ initio total-energy calculations using a plane-wave basis set. Phys. Rev. B Condens. Matter 54, 11169-11186 (1996)

36. Kresse, G. \& Furthmüller, J. Efficiency of ab-initio total energy calculations for metals and semiconductors using a plane-wave basis set. Comput. Mater. Sci. 6, 15-50 (1996).

37. PE, B. Projector augmented-wave method. Phys. Rev. B Condens. Matter 50, 17953-17979 (1994).

38. Perdew, J. P., Burke, K. \& Ernzerhof, M. Generalized gradient approximation made simple. Phys. Rev. Lett. 77, 3865-3868 (1996).

39. Zhou, F., Marianetti, C. A., Cococcioni, M., Morgan, D. \& Ceder, G. Phase separation in $\mathrm{Li}_{x} \mathrm{FePO}_{4}$ induced by correlation effects. Phys. Rev. B 69 201101-201104 (2004).

40. Zhou, F., Cococcioni, M., Marianetti, C. A., Morgan, D. \& Ceder, G. First-principles prediction of redox potentials in transition-metal compounds with LDA $+U$. Phys. Rev. B 70, 35-40 (2004)
41. Wang, L., Maxisch, T. \& Ceder, G. Oxidation energies of transition metal oxides within the GGA + U framework. Phys. Rev. B 73, 195107 (2006).

42. Vladimir, I. A., Aryasetiawan, F. \& Lichtenstein, A. I. First-principles calculations of the electronic structure and spectra of strongly correlated systems: the LDA + U method. J. Phys.: Condens. Matter 9, 767 (1997).

43. Nytén, A., Abouimrane, A., Armand, M., Gustafsson, T. \& Thomas, J. O. Electrochemical performance of $\mathrm{Li}_{2} \mathrm{FeSiO}_{4}$ as a new Li-battery cathode material. Electrochem. Commun. 7, 156-160 (2005).

44. Sirisopanaporn, C., Masquelier, C., Bruce, P. G., Armstrong, A. R. \& Dominko, R. Dependence of $\mathrm{Li}_{2} \mathrm{FeSiO}_{4}$ electrochemistry on structure. J. Am. Chem. Soc. 133 1263-1265 (2011).

45. Wang, L. et al. Crystal orientation tuning of $\mathrm{LiFePO}_{4}$ nanoplates for high rate lithium battery cathode materials. Nano Lett. 12, 5632-5636 (2012).

46. Song, $H$. J. et al. $\mathrm{Li}_{2} \mathrm{MnSiO}_{4}$ nanorods-embedded carbon nanofibers for lithium-ion battery electrodes. Electrochim. Acta 180, 756-762 (2015).

47. Yang, J. L. et al. Graphene activated 3D-hierarchical flower-like $\mathrm{Li}_{2} \mathrm{FeSiO}_{4}$ for high-performance lithium-ion batteries. J. Mater. Chem. A 3, 16567-16573 (2015).

48. Yamashita, T. \& Hayes, P. Analysis of XPS spectra of Fe ${ }^{2+}$ and $\mathrm{Fe}^{3+}$ ions in oxide materials. Appl. Surf. Sci. 254, 2441-2449 (2008).

49. Rangappa, D., Murukanahally, K. D., Tomai, T., Unemoto, A. \& Honma, I. Ultrathin nanosheets of $\mathrm{Li}_{2} \mathrm{MSiO}_{4}(\mathrm{M}=\mathrm{Fe}, \mathrm{Mn})$ as high-capacity Li-ion battery electrode. Nano Lett. 12, 1146-1151 (2012).

50. Masese, T. et al. Crystal structural changes and charge compensation mechanism during two lithium extraction/insertion between $\mathrm{Li}_{2} \mathrm{FeSiO}_{4}$ and $\mathrm{FeSiO}_{4}$. J. Phys. Chem. C. 119, 10206-10211 (2015).

51. LV, D. et al. Understanding the high capacity of $\mathrm{Li}_{2} \mathrm{FeSiO}_{4}$ : in situ XRD/XANES study combined with first-principles calculations. Chem. Mater. 25, 2014-2020 (2013).

52. Eames, C., Armstrong, A. R., Bruce, P. G. \& Islam, M. S. Insights into changes in voltage and structure of $\mathrm{Li}_{2} \mathrm{FeSiO}_{4}$ polymorphs for lithium-ion batteries. Chem. Mater. 24, 2155-2161 (2012).

53. Zhu, H., Wu, X., Zan, L. \& Zhang, Y. Superior electrochemical capability of $\mathrm{Li}_{2} \mathrm{FeSiO}_{4} / \mathrm{C} / \mathrm{G}$ composite as cathode material for Li-ion batteries. Electrochim. Acta 117, 34-40 (2014).

54. Bai, J. et al. Nanostructured $0.8 \mathrm{Li}_{2} \mathrm{FeSiO}_{4} / 0.4 \mathrm{Li}_{2} \mathrm{SiO}_{3} / \mathrm{C}$ composite cathode material with enhanced electrochemical performance for lithium-ion batteries. J. Mater. Chem. 22, 12128 (2012).

55. LV, D. et al. A novel $\mathrm{Li}_{2} \mathrm{FeSiO}_{4} / \mathrm{C}$ composite: synthesis, characterization and high storage capacity. J. Mater. Chem. 21, 9506 (2011).

56. Yang, J. et al. Hierarchical shuttle-like $\mathrm{Li}_{2} \mathrm{FeSiO}_{4}$ as a highly efficient cathode material for lithium-ion batteries. J. Power Sources 242, 171-178 (2013).

57. Jiang, $X$. et al. Synthesis of novel morphologies of $\mathrm{Li}_{2} \mathrm{FeSiO}_{4} / \mathrm{C}$ micro/nano composites by a facile hydrothermal method. RSC Adv. 4, 39889-39893 (2014).

58. Zhu, H., Wu, X., Zan, L. \& Zhang, Y. Three-dimensional macroporous graphene$\mathrm{Li}_{2} \mathrm{FeSiO}_{4}$ composite as cathode material for lithium-ion batteries with superior electrochemical performances. ACS Appl. Mater. Interfaces 6, 11724-11733 (2014).

59. $\mathrm{Hu}$, L. et al. Lithium storage properties of in situ synthesized $\mathrm{Li}_{2} \mathrm{FeSiO}_{4}$ and $\mathrm{LiFeBO}_{3}$ nanocomposites as advanced cathode materials for lithium ion batteries. J. Mater. Chem. A 3, 23368-23375 (2015).

60. $\mathrm{Lu}, \mathrm{X}$. et al. Rate-dependent phase transitions in $\mathrm{Li}_{2} \mathrm{FeSiO}_{4}$ cathode nanocrystals. Sci. Rep. 5, 8599 (2015).

61. Wagner, N., Svensson, A. M. \& Vullum-Bruer, F. Flame-made lithium transition metal orthosilicates. Electrochim. Acta 203, 246-256 (2016).

62. Kalantarian, M. M. et al. Understanding non-ideal voltage behaviour of cathodes for lithium-ion batteries. J. Mater. Chem. A 2, 19451-19460 (2014).

63. Lee, $\mathrm{H}$. et al. Origin of poor cyclability in $\mathrm{Li}_{2} \mathrm{MnSiO}_{4}$ from first-principles calculations: layer exfoliation and unstable cycled structure. Chem. Mater. 26 3896-3899 (2014)

64. Seo D.-H., Kim H., Park I., Hong J. \& Kang K. Polymorphism and phase transformations of $\mathrm{Li}_{2-x} \mathrm{FeSiO}_{4}(0 \leq x \leq 2)$ from first principles. Physical Rev. B 84, 220106 (2011).

65. Zhao, Y., Peng, L., Liu, B. \& Yu, G. Single-crystalline LiFePO $_{4}$ nanosheets for highrate Li-ion batteries. Nano Lett. 14, 2849-2853 (2014).

66. Shimon, L. J. W., Vaida, M., Addadi, L., Lahav, M. \& Leiserowitz, L. Molecular recognition at the solid-solution interface: a relay mechanism for the effect of solvent on crystal growth and dissolution. J. Am. Chem. Soc. 112, 6215-6220 (1990). 